days, and 44 for 180 days. Fifty patients received placebo and $\mathbf{4 7}$ cimetidine.

Severe upper gastrointestinal bleeding occurred in 12 patients (seven men, five women). None of them had a history of peptic ulcer, and the examinations of the upper gastrointestinal tract before transplantation had yielded normal results. During the acute bleeding episode six of these patients were examined either radiographically or endoscopically. Two had an acute gastric ulcer, and four had diffuse bleeding from gastric or duodenal erosions. Eleven patients had received placebo and one cimetidine. This difference was significant $\left(\chi^{2}=7 \cdot 07\right.$, $\mathrm{p}<0.01$ ). All bleeding episodes occurred within the first 30 days after renal transplantation (median 12, range 1-30 days).

Ten patients given placebo and 12 given cimetidine had their rena! graft removed after five to 145 (median 35) days because of rejection. This difference was not significant $\left(\chi^{2}=0 \cdot 167\right)$.

\section{Discussion}

Only a few, retrospective studies of the prophylactic use of cimetidine in renal transplant recipients have been reported. These have compared the incidence of upper gastrointestinal haemorrhage in patients treated with cimetidine with that in historic controls not receiving cimetidine. In such retrospective studies Jones et al and Roermund $e t$ al found a significant effect of cimetidine ${ }^{78}$ and Garvin et al reported some effect. ${ }^{9}$ In the only prospective study reported Schiessel et al found no significant effect of cimetidine after renal transplantation in 55 patients. ${ }^{10}$ Primack suggested that treatment with cimetidine might increase the incidence of allograft rejection. ${ }^{11}$ Schiessel et al did not confirm this. ${ }^{10}$

Our study showed that in most patients cimetidine prevents upper gastrointestinal bleeding after renal transplantation. This accords with the results of the previous retrospective studies. In the prospective study of Schiessel et al three patients given cimetidine and two given placebo had upper gastrointestinal bleeding. ${ }^{10}$ The apparent difference between these findings and those of our study may be explained by the different number of patients studied.

In conclusion, our study showed that cimetidine acts as effective and safe prophylaxis against upper gastrointestinal bleeding after renal transplantation. There was no indication that it influenced the incidence of rejection of the renal graft.

\section{References \\ 1 Rasmussen K, Christiansen J, Nielsen OV, McNair A, Sørensen MB. Gastro- duodenal ulcer in kidney-transplanted patients receiving immunosuppressive treatment. Acta Chir Scand 1975;141:61-4. \\ 2 Berg B, Groth CG, Magnusson G, Lundgren G, Ringden $O$. Gastrointestinal complications in 248 kidney transplant recipients. Scand $\mathcal{f}$ Urol Nephrol 1975 suppl 29:19-20. \\ Nephrol Nephrol 1975 ;suppl $29: 21-3$. \\ Chisholm GD, Mee AD, Williams G, Gastro JE, Baron JH. Peptic ulceration gastric secretion, and renal transplantation. Br Med F 1977; i:1630-3. \\ We in the renal transplant patient. Ann Surg 1977;186:17-21. \\ Doherty CC. Cimetidine prophylaxis after renal transplantation. Br Med 71978 i:717. \\ 7 Jones RH, Rudge CJ. Bewick M, Parsons V, Weston MJ. Cimetidine : prophylaxis against upper gastrointestinal haemorrhage after renal transplantation. Br Med $f$ \\ 8 Roermund HPC, Tiggeler RGW, Berden JHM, Lier HJJ, Koene RAP. Cimeti- dine prophylaxis after renal transplantation. Clin Nephrol 1982;18:39-42. \\ 9 Garvin PJ, Carney K, Castaneda M, Codd JE. Peptic ulcer disease following transplantation: the role of cimetidine. $A m \mathcal{F}$ Surg 1982;144:545-8. \\ (t) prevent gastro- duodenal ulceration and bleeding after renal transplantation. Surgery $1981 ; 90$ \\ 11 Primack WA. Cimetidine and renal-allograft rejection. Lancet 1978;i:824-5.}

\title{
Anaphylactic reaction to aprotinin despite negative ocular sensitivity tests
}

\author{
GODFREY A LAFERLA, WILLIAM R MURRAY
}

\begin{abstract}
A man with a history of pancreatitis was given aprotinin intravenously just before endoscopic retrograde pancreatography. Despite negative sensitivity tests with aprotinin eye drops he developed a profound anaphylactic reaction on intravenous administration of the drug.

Ocular sensitivity tests may not predict severe anaphylactic reactions to intravenous aprotinin.
\end{abstract}

\section{Introduction}

Serious allergic reactions to aprotinin occur in less than $0.1 \%$ of patients receiving this drug. ${ }^{1}$ We report on a man who,

Department of Surgery, Western Infirmary, Glasgow G11 6NT GODFREY A LAFERLA, FRCS, registrar

WILLIAM R MURRAY, MD, FRCS, senior lecturer

Correspondence to: $\mathrm{Mr} \mathrm{G} \mathrm{LaFerla.}$ despite negative ocular sensitivity tests, had a severe anaphylactic reaction after the intravenous administration of aprotinin.

\section{Case report}

A 44 year old man with a clinical history suggestive of chronic pancreatitis secondary to alcohol abuse was referred to this hospital for endoscopic retrograde pancreatography.

He gave a history of having been admitted several times to the referring hospital with upper abdominal pain, often associated with appreciable hyperamylasaemia. He was usually treated conservatively with intravenous fluids and analgesics and according to the records had twice received an infusion of aprotinin. In June 1982 he had undergone suction drainage of a ruptured pancreatic pseudocyst, after which he had further episodes of abdominal pain, often necessitating admission to hospital and treatment with narcotic analgesics.

Recent investigations had shown normal haematology and biochemistry. Ultrasound scanning of the pancreas showed some dense echoes in the head and body; the tail, however, could not be clearly defined. A Lundh test meal was indicative of early pancreatic insufficiency.

Our policy with patients undergoing endoscopic retrograde pancreatography who have a history of pancreatitis was to administer 500000 Kallikrein inhibiting units (KIU) aprotinin intravenously, 
just before endoscopy and after ocular testing for sensitivity. The sensitivity test was carried out in this patient with aprotinin eye drops at three strengths $(5,10$, and $50 \mathrm{KIU} / \mathrm{ml})$ at five minute intervals. He showed no evidence of acute conjunctivitis, thereby suggesting no allergy.

Despite the negative sensitivity test, when aprotinin was administered intravenously he developed a profound anaphylactic reaction with an unrecordable pulse rate and blood pressure. Active resuscitation by ventilation, massive fluid transfusion, and intravenous steroids was successful. After observation for 24 hours in the intensive care unit he was transferred to a surgical ward and discharged the next day.

\section{Discussion}

In our experience, injection of the pancreatic duct in patients undergoing endoscopic retrograde cholangiopancreatography is associated with hyperamylasaemia in $70 \%$ and acute pancreatitis in $21 \%$ of patients, patients with a history of pancreatitis being at particular risk. We therefore routinely intravenously administer the protease inhibitor aprotinin, in a bolus dose of $500000 \mathrm{KIU}$, as prophylaxis immediately before the procedure. No reports have been published detailing the method and value of ocular pretesting for aprotinin sensitivity, but it is recommended by the manufacturer of the drug (Bayer UK). Similar testing has been used for contrast media in radiology ${ }^{2}$ with varying support. ${ }^{3}$

This case highlights the fact that, although the ocular sensitivity test may correlate well for mild allergic reactions, it may not predict severe anaphylactic reactions or sudden death after the administration of aprotinin to a susceptible patient. This fact must raise doubts about the efficacy of such sensitivity testing before using aprotinin. This case also indicates that prophylactic treatment with aprotinin should be avoided in patients who have received the drug in the past, as sensitisation may not be detected by conventional testing.

\section{References}

1 Bailey AJM, ed. Data sheet compendium. London: Datapharm Publications, 1984:135.

2 Archer VW, Harris ID. An ocular test for sensitivity to Diodrast prior to intravenous urography. American fournal of Roentgenology and Radium Therapy 1942;48: 763-5.

3 Fischer $\mathrm{HW}$, Doust VL. An evaluation of pretesting in the problem of serious and fatal reactions to excretory urography. Radiology 1972;103:497-501.

(Accepted 14 August 1984)

\title{
Intravenous gammaglobulin treatment in patients with hypogammaglobulinaemia
}

\author{
A SO, M K BRENNER, I D HILL, G L ASHERSON, A D B WEBSTER
}

\begin{abstract}
Intravenous gammaglobulin was compared with the standard British intramuscular preparation in patients with hypogammaglobulinaemia and chronic bronchitis. Five patients were given six months' treatment with the weekly intramuscular preparation and six months' treatment with intravenous gammaglobulin given once every 18 days. During the trial they recorded symptoms of infection, absence from work, and sputum volume; lung function tests were performed during the intravenous treatment. The half life of the intravenous IgG and changes in serum IgG and Clq concentrations were also measured in seven other patients who received intravenous gammaglobulin every two weeks for 12 weeks. IgG concentrations, sputum volume, and infection scores were significantly better during intravenous treatment and there were no adverse effects from the intravenous gammaglobulin.

These five patients were significantly more healthy
\end{abstract} when they received an intravenous gammaglobulin

Clinical Research Centre, Harrow, Middlesex HA1 3UJ

A SO, MRCP, registrar, division of immunology and rheumatology

$M$ K BRENNER, MRCP, PHD, senior registrar and research fellow

I D HILL, DSC, member of scientific staff, division of computing and statistics

G L ASHERSON, DM, FRCP, head, division of immunological medicine

A D B WEBSTER, FRCP, consultant physician and senior scientist, division of immunological medicine

Correspondence to: Dr A D B Webster. preparation, probably because the intravenous preparation increased serum IgG concentrations. Although longer studies are needed, intravenous gammaglobulin should be considered for patients with severe chest disease and those who cannot tolerate intramuscular injections.

\section{Introduction}

It has been standard practice in England to give patients with symptomatic hypogammaglobulinaemia weekly intramuscular injections of gammaglobulin, which are painful and sometimes cause anaphylactic type reactions. ${ }^{1}$ We report a small comparative trial between the standard British intramuscular preparation and an intravenous gammaglobulin.

\section{Patients and methods}

We studied five patients with primary hypogammaglobulinaemia (serum immunoglobulin concentrations: IgG $<2, \operatorname{IgA}<0 \cdot 1$, and IgM $<0.1 \mathrm{~g} / \mathrm{l})$ and chronic bronchitis who had been receiving weekly intramuscular injections of gammaglobulin for many years. Each patient entered the trial for 12 months and received a total of six months' treatment with intravenous gammaglobulin (Immunoglobulin SRK, Sandoglobulin) ${ }^{2}$ and six months' treatment with intramuscular gammaglobulin (Blood Products Laboratory, England). To control for seasonal variation in infection rates we gave each regimen for an equal amount of time in the winter (from October to March). The intravenous gammaglobulin was given in a dose of $200 \mathrm{mg} / \mathrm{kg}$ body weight once every 18 days and the intramuscular gammaglobulin in a dose of $25 \mathrm{mg} / \mathrm{kg}$ once a week.

Patients kept daily records of symptoms of infection and absences from work, and recorded their sputum volume on either Saturday or 